\title{
OCCURRENCE OF URINARY TRACT INFECTION IN CHILDREN WITH NEPHROTIC SYNDROME IN A TERTIARY CARE HOSPITAL
}

\author{
Vishwanath ${ }^{1}$,Jaidev Mangalore Devdas ${ }^{2}$, Mario Joseph Bukelo ${ }^{3}$ \\ 1 Post Graduate Resident, Department of Paediatrics, Father Muller Medical College, Manglore. \\ ${ }^{2}$ Assistant Professor, Department of Paediatrics, Father Muller Medical College, Manglore. \\ ${ }^{3}$ Senior Resident, Department of Paediatrics, Father Muller Medical College, Manglore.
}

\section{ABSTRACT}

\section{BACKGROUND}

Nephrotic Syndrome (NS) is among the most common chronic kidney diseases occurring in childhood. Defense mechanisms are impaired in patients with NS. Immuno-compromised status of NS can result in increased susceptibility to various infections, which could be potentially serious and life-threatening without prompt diagnosis and treatment. The occurrence of Urinary Tract Infection (UTI) is about $30 \%$ in children with nephrotic syndrome; however, it often goes undiagnosed. The present study is a prospective and a descriptive study designed to estimate the occurrence of urinary tract infection in children diagnosed to have NS.

\section{METHODS}

This is a prospective and descriptive study, which was conducted over a period of one year and included patients diagnosed to have NS who attended to the Paediatric Outpatient Department or were admitted at Father Muller Medical College Hospital over a study period of one year. Clean catch midstream urine samples were obtained from all the patients. Urine examination including routine analysis, microscopy, culture and sensitivity was done as per hospital standard policies.

\section{RESULTS}

This study included 30 children, out of which nine (30\%) were diagnosed with culture positive UTI ( 6 males and 3 females). The most common organism isolated from the urine culture was Escherichia coli, followed by Proteus, Enterococcus, Pseudomonas and Klebsiella, which was statistically significant (Binomial test $\mathrm{p}=0.043$ ). Among the 9 cases who had culture positive UTI 3 were newly diagnosed NS and 6 were relapse NS. There was no significant difference between the two groups with regard to sex and age distribution.

\section{CONCLUSION}

This study concludes that urinary tract infections are an important but often under diagnosed infection in children with nephrotic syndrome. All children with nephrotic syndrome newly diagnosed or relapse should be screened for the presence of UTI.

\section{KEYWORDS}

Nephrotic Syndrome (NS), Urinary Tract Infection (UTI), Relapse.

HOW TO CITE THIS ARTICLE: Vishwanath, Devdas JM, Bukelo MJ. "Occurrence of urinary tract infection in children with nephrotic syndrome in a tertiary care hospital." Journal of Evolution of Medical and Dental Sciences 2015; Vol. 4, Issue 105, December 31; Page: 17014-17016, DOI: 10.14260/jemds/2015/2573

\section{INTRODUCTION}

Nephrotic Syndrome (NS) is among the most common chronic kidney diseases occurring in childhood. The incidence of idiopathic NS in Asian population is reported at 2-3 cases per $1,00,000$ children. ${ }^{1}$ Defense mechanisms are impaired in patients with NS due to its consequences of tissue edema, urinary loss of immunoglobulin, complement and secondary effects to its treatment including steroids and other immunosuppressants. ${ }^{2}$ Immuno-compromised status of NS can result in increased susceptibility to various infections, which could be potentially serious and life-threatening without prompt diagnosis and treatment. ${ }^{3}$

Financial or Other, Competing Interest: None.

Submission 04-12-2015, Peer Review 07-12-2015,

Acceptance 26-12-2015, Published 30-12-2015.

Corresponding Author:

Dr. Vishwanath,

Post Graduate Resident,

Department of Paediatrics,

Father Muller Medical College,

Manglore.

E-mail: vishi0207@gmail.com

DOI:10.14260/jemds/2015/2573
Urinary Tract Infection (UTI) is a common bacterial infection in infants and children. The risk of having a UTI before the age of 14 years is approximately $1-3 \%$ in boys and $3-10 \%$ in girls. ${ }^{4}$ The prevalence of UTI varies from $4 \%$ in neonatal period to $0.4 \%$ in the school and pre-school age children. ${ }^{4}$ The diagnosis of UTI is often missed in infants and young children, as urinary symptoms are minimal and often non-specific.

The occurrence of Urinary Tract Infection (UTI) is about $30 \%$, in children with nephrotic syndrome, however it often goes undiagnosed. ${ }^{1}$ Other infections which occur in children with NS include spontaneous bacterial peritonitis, bacteraemia, sepsis, cellulitis and pneumonia. ${ }^{5-8}$

Relapses in nephrotic syndrome are often temporally associated with increased occurrence of infection. ${ }^{3}$

Although there have been several studies in the past pertaining to infections in nephrotic syndrome, most have been from the developed countries and in hospitalized patients. $^{1-3}$ As majority of these children are managed on an outpatient basis, these studies might not reflect the true spectrum of illness in our setting. 
There is a paucity of population based studies in literature addressing the trends and potential factors associated with the infections in children with NS. The present study was conducted to investigate the trends of the occurrence and etiology of urinary tract infections in children with nephrotic syndrome mainly outpatients in our hospital a tertiary care unit.

\section{MATERIALS AND METHODS}

\section{Source of Data and Study design}

A prospective and descriptive study of all the patients with a diagnosis of nephrotic syndrome who attended to the Pediatric Outpatient Department (OPD) or were admitted at Father Muller Medical College hospital over a study period of one year from September 2014 to August 2015.

\section{Method of Collection of Data}

Thirty patients who have full filled the criteria of nephrotic syndrome (According to ISKDC) were included in the present study. The objective of the study were explained and written consent was obtained from the parents, prior to inclusion in the study.

A detailed clinical examination was performed and finding were noted in the data sheet. Clean catch midstream urine samples were obtained from all the patients. Urine examination including routine analysis, microscopy, culture and sensitivity was done as per hospital standard policies.

\section{Sample Size}

A sample size of 30 children with nephrotic syndrome admitted in the pediatric ward or attended the pediatric OPD during the study period.

\section{Inclusion Criteria}

All patients below the age group of 15 yrs. who attended paediatric OPD/IPD and were diagnosed as nephrotic syndrome (New cases or relapse) according to ISKDC with or without the symptoms suggestive of UTI.

\section{DIAGNOSIS OF NEPHROTIC SYNDROME}

ISKDC (International Study of Kidney Diseases in Children) Criteria for nephrotic syndrome were eligible for inclusion:

1. Edema.

2. Proteinuria: Urine protein $>3+$ or $\geq 40 \mathrm{mg} / \mathrm{m}^{2}$ per hour by sulfosalicylic acid test.

3. Protein creatinine ratio $>2$.

4. Hypoalbuminemia (Serum albumin $\leq 2.5 \mathrm{~g} / \mathrm{dl}$ ). ${ }^{9,10}$

\section{Relapse of Nephrotic Syndrome}

Reappearance of proteinuria $\geq 40 \mathrm{mg} / \mathrm{m}^{2}$ per hour or $>3+$ by sulfosalicylic acid test for three consecutive days with or without oedema in a child who had attained remission previously. $\cdot 9,10$

\section{Exclusion Criteria}

1. Nephrotic syndrome patients already diagnosed with UTI and on antibiotics.

2. Relapse patients who are already included in the study.

\section{Method of Study}

A total of 30 children of paediatric age group (Up to $15 \mathrm{yrs}$.) were included.

\section{Collection of Urine Specimen}

The specimen for urine culture was obtained carefully to prevent contamination. A clean-catch midstream urine specimen was directly collected in a sterile container. Antiseptic washes and forced prepucial retraction were not advised.

\section{Definition of Urinary Tract Infection}

A bacterial colony count of $>10^{5} / \mathrm{ml}$ of a single species in a midstream clean catch sample of urine. ${ }^{4}$

\section{Statistical Methods Used}

The collected statistical data were presented as frequency, percentage, analyzed using Fisher exact and binomial tests. ' $\mathrm{P}$ ' value $<0.05$ was considered significant.

\begin{tabular}{|c|c|c|}
\hline $\begin{array}{c}\text { Urinary Tract } \\
\text { Infection }\end{array}$ & No. of Patients & Percentage \\
\hline POSITIVE & 9 & $30 \%$ \\
\hline NEGATIVE & 21 & $70 \%$ \\
\hline TOTAL & $\mathbf{3 0}$ & $\mathbf{1 0 0 \%}$ \\
\hline Table 1: Occurrence of UTI in Nephrotic Syndrome
\end{tabular}

Binomial test $p=0.043$

\begin{tabular}{|c|c|c|}
\hline & UTI-PRESENT & UTI-ABSENT \\
\hline Male & 6 & 14 \\
\hline Female & 3 & 7 \\
\hline TOTAL & 9 & $\mathbf{2 1}$ \\
\hline \multicolumn{2}{|c|}{$\begin{array}{c}\text { Table 2: Gender distribution in UTI } \\
\text { Fisher's exact test } p=0.656\end{array}$} \\
\hline
\end{tabular}

\begin{tabular}{|c|c|c|}
\hline AGE & PRESENT & ABSENT \\
\hline$<3$ years & 2 & 4 \\
\hline 3-8 years & 6 & 14 \\
\hline $8-15$ years & 1 & 3 \\
\hline TOTAL & 9 & $\mathbf{2 1}$ \\
\hline \multicolumn{2}{|c|}{ Table 3: Age distribution in UTI Fishers } \\
exact test p= 0.961
\end{tabular}

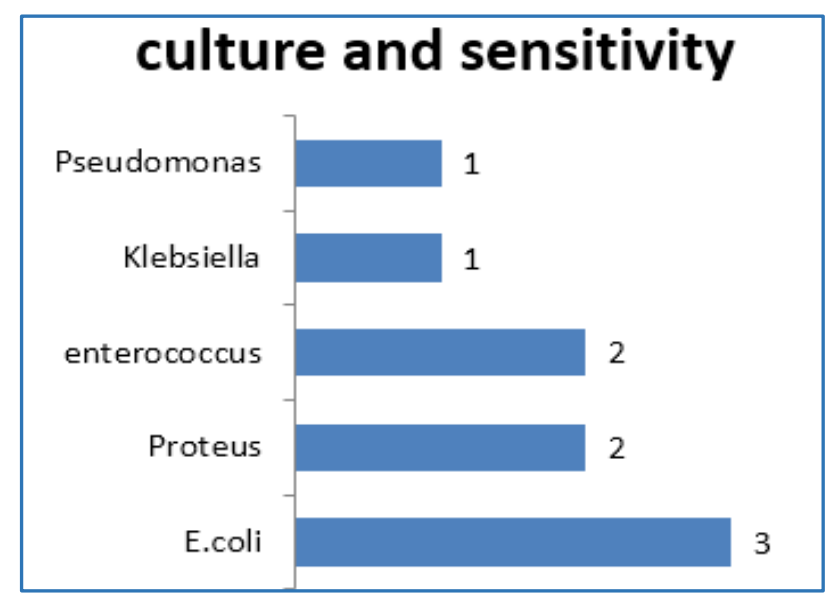

Graph 1

\section{RESULT}

The study was conducted over a period of 12 months and consisted of 30 children ( 20 males and 10 females). During this period, out of 30 children in the study nine had culture positive UTI ( 6 males and 3 females). The most common organism 
isolated from the urine culture was Escherichia coli followed by proteus, enterococcus, pseudomonas and Klebsiella (Graph no.1), which was statistically significant (Binomial test $\mathrm{p}=0.043$ ). Of the 9 cases who had culture positive UTI, 3 were newly diagnosed NS and 6 were relapse NS. There was no significant difference between the two groups with regard to sex and age distribution. (Table 2 and 3 ).

\section{DISCUSSION}

The child with nephrotic syndrome represents an immunecompromised host and hence is susceptible to a variety of infections. ${ }^{10}$ This could be due to decreased serum immunoglobulin, protein deficiency, decreased bactericidal activity of the leukocytes, immunosuppressive therapy, decreased perfusion of the spleen caused by hypovolemia and loss in the urine of a complement factor (Properdin factor 3) that opsonizes certain bacteria. 9,10

The pressure on the collecting system by edematous pyramids causes narrowing and functional obstruction to the flow of urine, further predisposing them to UTI. Of all the infections in children, Urinary Tract Infections (UTI) are significant due to their association with vesicoureteric reflux and propensity for long term damage. ${ }^{9,10}$ Information regarding their prevalence in nephrotic children is scant and conflicting, although advances in knowledge and use of medications have improved outcomes of NS and reduced comorbidity and mortality of NS in recent years. ${ }^{1-3}$

The occurrence of UTI in nephrotic children in our study was $30 \%$, which is comparable to the study done by ChangChing et al., where incidence of UTI in nephrotic syndrome was also $30 \%$. The commonest infection was pneumonia (49\%) second being UTI (30\%), bacteraemia/sepsis (11\%), peritonitis (11\%) and cellulitis (5\%). ${ }^{1}$

In a similar study done by S. Gulati et al. titled urinary tract infection in nephrotic syndrome reported that urinary tract infections are very common (13\%), but often goes undiagnosed. ${ }^{2}$

P. Senguttuvan et al., in their descriptive study titled infections encountered in childhood nephrotics in a pediatric renal unit reported $46 \%$ to be UTI in their study group of 199 subjects. ${ }^{6}$

Similar study done by Alwadhi et al. titled clinical profile of children with nephrotic syndrome not on glucocorticoid therapy concluded that infection is widely prevalent among that urinary tract infection $(22.8 \%)$ and causative agents being Gram negative organisms Escherichia coli, Proteus, Klebsiella, Enterococcus, which is comparable with our work.
The limitations of our study is a relatively small sample size due to which the data cannot be extrapolated to consider a large population. Further studies would be the need of hour using a larger number.

\section{CONCLUSION}

We conclude that urinary tract infections are an important, but often under diagnosed infection in children with nephrotic syndrome. All children with nephrotic syndrome newly diagnosed or relapse should be screened for the presence of UTI.

\section{REFERENCES}

1. Wei C, Yu I, Lin H, et al. Occurrence of infection among children with nephrotic syndrome during hospitalizations. Nephrology. 2012;17(8):681-688.

2. Gulati S, Kher V, Gupta A, Arora P, Rai P, Sharman R. Urinary tract infections in nephrotic syndrome. The Pediatric Infectious Disease Journal. 1996;15(3):237-240.

3. Ibadin MO. The prevalence of urinary tract infection in childhood nephrotic syndrome, Nigerian Journal of Paediatrics. 1997;24:40-44.

4. Agarwal Vinay, Bagga Arvind, Srivasthava RN. Recommendations, consensus statement on Management of UTI, Indian Pediatrics 2001;38:1106-1115.

5. Adeleke SI and Asani MO. Urinary Tract Infection in children with nephrotic syndrome in Kano, Nigeria, Annals of African medicine, 2009;8(1):38-41.

6. Soeiro E, Koch V, Fujimura M, et al. Influence of nephrotic state on the infectious profile in childhood idiopathic nephrotic syndrome. Rev Hosp Clin 2004;59(5)

7. Senguttuvan $\mathrm{P}$, Ravanan $\mathrm{K}$, Prabhu N, et al. Infections encountered in childhood nephrotics in a pediatric renal unit, Indian J Nephrol, 2004;14(9):85-88.

8. Alwadhi R, Mathew J, Rath B. Clinical profile of children with nephrotic syndrome, not on glucocorticoid therapy, but presenting with infection. Journal of Paediatrics and Child Health. 2004;40(1-2):28-32.

9. Kidney International, nephrotic syndrome in children: Prediction of histopathology from clinical and laboratory characteristics at time of diagnosis 1978;13:159-165.

10. Ellis D Avener, Jack S Elder and Priya Pais. Nephrotic syndrome and urinary tract infections. Nelson's text book of Paediatrics: 19(2):1801-1807. 